DOI: $10.4274 /$ jarem.galenos.2020.2767

J Acad Res Med 2020;10(2):133-7

\title{
Cost Analysis in Knee Revision Arthroplasty: A Study at the Research and Training Hospital in Turkey
}

\author{
(1) Ferdi Dırvar1', (1) Sevda Uzun Dırvar1', (1) Timur Yıldırım1, (10) Ömer Cengiz2, (1) Mehmet Ali Talmaç3 \\ ${ }^{1}$ Health Sciences University Turkey, Metin Sabancı Baltalimanı Bone and Joint Diseases Training and Research Center, Clinic of Orthopedics \\ and Traumatology, İstanbul, Turkey \\ ${ }^{2}$ Muş State Hospital, Clinic of Orthopedics and Traumatology, Muş, Turkey \\ ${ }^{3}$ Şişli Hamidiye Etfal Training and Research Hospital, Clinic of Orthopedics and Traumatology, İstanbul, Turkey
}

Cite this article as: Dırvar F, Uzun Dırvar S, Yıldııım T, Cengiz Ö, Talmaç MA. Cost Analysis in Knee Revision Arthroplasty: A Study at the Research and Training Hospital in Turkey. J Acad Res Med 2020;10(2):133-7

\begin{abstract}
Objective: This study aimed to investigate the costs covered by the hospital during inpatient treatment of patients who underwent knee revision arthroplasty in the orthopedics and traumatology clinics of a public hospital and compare with the invoiced amount.

Methods: The demographic information and revision reasons of 50 patients who underwent total knee revision arthroplasty in a public hospital between 01.01.2016 and 30.09.2017 were determined using hospital information management system records. The patients were categorized into two groups: septic and aseptic. For each patient, the costs of medical consumables, medicine/serum, medical treatment, surgery, anesthesia, imaging services, laboratory procedures, blood and blood products, meal and companion costs, device depreciation expenses, consultation, control examination, preoperative patient preparation stage, surgery, visit and other costs were calculated separately during inpatient treatment.

Results: The average total cost of a patient was $24,005.00 \mathrm{TL}$, whereas the average invoice amount was $21,490.00 \mathrm{TL}$, with a difference of 2,515.00 $\mathrm{TL}$. This difference was 3,193.00 TL and 2,166.00 TL in the septic and aseptic groups, respectively. In the septic group, the duration of hospital stay, medication, treatment, surgery, anesthesia, laboratory, imaging, blood center, consultation, visit, meal cost, total cost, and invoice amount were significantly higher than the aseptic group ( $p \square 0.05)$.

Conclusion: Regulations by the social security institution are needed to ensure the fiscal sustainability of the public hospital's. In addition, following the medical and technical innovations in revision surgery can help reduce the costs.
\end{abstract}

Keywords: Revision, knee joint, arthroplasty, cost analysis, hospital economics

\section{INTRODUCTION}

The Nationwide Inpatient Sample (United States) surveys of hospital discharge records projected the demand for primary total knee arthroplasty (TKA) to increase by $673 \%$ from 450,000 (95\% prediction interval, 425,000 to 477,000 ) in 2005 to 3.48 million procedures (95\% prediction interval, 2.95 to 4.14 million) by 2030 . The results of the same report projected the TKA revisions to increase from 38,300 (95\% prediction interval, 32,600 to 44,300 ) in 2005 to 268,200 ( $95 \%$ prediction interval, 192,700 to 381,400 ) by 2030 (an increase of 601\%) (1).

For an economical operation and sustainability of a hospital, the costs of complex cases requiring higher budgets should cover the variable costs per patient, which enables to cover the hospital's total fixed costs by the income from other more common procedures (2).

ORCID IDs of the authors: F.D. 0000-0003-1789-3637; S.U.D. 0000-0001-7943-7472; T.Y. 0000-0003-0291-7632; Ö.C. 0000-0003-1743-4828; M.A.T. 0000-0001-7734-6438. 
The calculation of the costs of the services in hospital's is a difficult issue because common costs are wide in hospitals, diverse health services are offered, and the complexity of service units causes difficulties in cost estimations. Public hospitals offer profit-free services, and no direct relationship is found between the income from service provision and cost of services. It is only possible to determine whether a hospital gains or losses from a surgery by determining the costs in a real or real-like way. Diagnostic and treatment methods of health services financed by the Social Security Institution (SSI) in our country are indicated in the Health Practice Notifications (HPN) and annex lists, and HPN scores are compared in line with the opinions of experts based on the difficulty of the procedures $(3,4)$. The SSI considering the cost estimates based on scientific cost analysis studies should be useful to determine the reimbursement prices to the hospitals (5).

This study aimed to investigate the costs covered by the hospital during the inpatient treatment of patients who underwent knee revision arthroplasty in the orthopedics and traumatology clinics of a public hospital and compare with the invoiced amount.

\section{METHODS}

After obtaining institutional review board approval, the demographic information and revision reasons of 50 patients who underwent total knee revision arthroplasty in a public hospital between 1 January, 2016 and 30 September, 2017 were determined using the Hospital Information Management System (HIMS) records. All total revision procedures due to infection and component loosening were included. The patients were categorized into two groups: septic and aseptic.

The treatment costs of patients in public hospitals in Turkey are maintained according to the lists in the Health Application Notification (HAN) and annexes in the appendix announced by the SSI. In these lists, a code has been determined for each surgical procedure, and the amount to be paid to the institution is indicated by the codes. The physician enters the code of each surgical procedure. In this study, the data of the patients with the code for total hip revision arthroplasty were included, but those with partial revision arthroplasty code were excluded. Two-stage revision arthroplasty surgeries in patients with septic origin were included. The duration and cost of hospitalization for each stage were added to the data set for each patient and included in the study.

For each patient, the costs of medical consumables (revision tibia and femur component, gloves, sutures, etc.), medicine/ serum costs, medical treatment costs (injections, transfusion, arterial catheterization, wound debridement, enema, vascular access, etc.), costs of surgery and anesthesia procedures (revision knee arthroplasty, joint debridement, implant removal, spacer application, anesthesia, epidural block, etc.), costs of imaging services (direct graph, length graph, MR, CT, reporting, etc.), costs of laboratory procedures (biochemistry, microbiology, etc.), costs of blood and blood products (erythrocyte suspension, FFP, etc.), patient meals and companion costs, device depreciation expenses, consultation, control examination, preoperative patient preparation stage, surgery, visit and other costs were calculated separately during the impatient treatment, and the cost of each patient covered by the hospital was determined after calculating the sum of all the abovementioned costs.

While doing these calculations, after the amounts of all the goods and services covered for each patient during inpatient treatment are determined through HIMS, the average purchasing unit prices of the goods and services used for these patients from the hospital purchasing unit, the goods and services procurement contracts, the point multiples determined by the laboratory and imaging service procurements, the billings paid to the Red Crescent Blood Center, the main scores and coefficients to be paid for the processes in the HPN annex lists, data of the salary trust department, warehouse records, data from other related units, and the expense determination tables in the cost analysis studies published by the Ministry of Health were used (4).

In accordance with the applicable legislation, the invoices according to the HPN and annex lists have been determined for each patient from the hospital records. The total costs covered and SSI bill amounts were compared to determine the difference. The study was approved by the University of Health Sciences, Metin Sabancı Baltalimanı Training and Research Hospital Expertise Education Committee in Medicine Observational Research Ethics Committee (approval number:16.10.2017-16). The demographic information was determined using HIMS records.

\section{Statistical Analysis}

The mean, standard deviation, median lowest, highest, frequency, and ratio values were used in the descriptive statistics. The distribution of the variables was measured using the KolmogorovSmirnov test. The Mann-Whitney $U$ test was used in the analysis of quantitative independent data, and chi-squared test was used in the analysis of qualitative independent data. SPSS 22.0 program (IBM Corp., Released 2013, IBM SPSS Statistics for Windows, Version 22.0. Armonk, NY, USA) was used in the analyses.

\section{RESULTS}

Of the 50 patients, 37 were women, and 13 were men, with a mean age of 69 years. The aseptic and septic groups were composed of 33 and 17 patients, respectively. Table 1 shows the data of patients undergoing knee revision arthroplasty and their costs. The average cost of a patient was 24,005.00 TL (Turkish Lira), whereas the average invoice amount was $21,490.00 \mathrm{TL}$, with a difference of 2,515.00 TL. When comparing patients who underwent surgeries for septic and aseptic reasons, the average cost of the surgery (two-stage) for septic and reasons was 28,968.00 TL and 21,448.00 $\mathrm{TL}$, respectively, whereas the invoice amount was $25,775.00 \mathrm{TL}$ and $19,282.00 \mathrm{TL}$, with a difference of 3,193.00 TL and 2,166.00 $\mathrm{TL}$, respectively.

The age and sex distribution, duration of the surgery, medical expenditure, patient acceptance, operation team, device depreciation, and companion expenses did not differ significantly 
in the aseptic and septic groups ( $p>0.05)$. In the septic group, the duration of hospital stay, medication, treatment, surgery, anesthesia, laboratory, imaging, blood center, consultation, visits, meal costs, total cost, and invoice amount were significantly higher than the aseptic group $(p<0.05)$ (Table 2).

\section{DISCUSSION}

The main purpose of the studies on the total cost of patients during inpatient treatment is to find possible ways to reduce the costs based on health care without compromising the quality of the health care services (6-10). However, cost analysis is difficult and time consuming. Administrative, financial, and medical data should be reliable to establish the direct cost. Necessary regulations must be made to ensure the presentation of the money spent on the patient when requested and the motivation of the staff responsible for providing services to the patient at the first instance should be increased, and the functionality in fulfilling their responsibility should be ensured (10).

In this study, the payment of the patients who underwent revision knee arthroplasty during inpatient treatment based on HPN prices by the SSI was made below the hospitalization cost. When the literature is examined, similar results are found in studies conducted by unit cost analysis (11). Because the number of patients who underwent revision knee arthroplasty is expected to increase in the future (1), we believe that SSI needs to make corrective actions, such as revision of HPN prices in revision knee arthroplasty to ensure the sustainability of financial resources in public hospitals.

Similar studies have reported that septic knee revision arthroplasty is significantly more costly than aseptic knee revision arthroplasty (12-14). In our study, the cost of inpatient treatment for septic-based revision knee arthroplasty was approximately 7,520.00 TL more than that for aseptic-based revision knee arthroplasty.

In the literature, blood products and drug expenditures are significantly higher in the inpatient treatment of septic-based revision surgery, and while analyzing the costs covered by the hospital in the cost analysis of septic total knee revision surgeries, two separate hospitalizations for the two-stage revision and personnel costs should be included in the costs (14). This study is significant because all costs during inpatient treatment covered by the hospital are calculated, and the duration of hospitalization, medicine, treatment, surgery, anesthesia, laboratory, imaging, blood center, consultation, visits, meal costs, total costs, and

\section{Table 1. Descriptive statistics of the data}

\section{Descriptive statistics of the data}

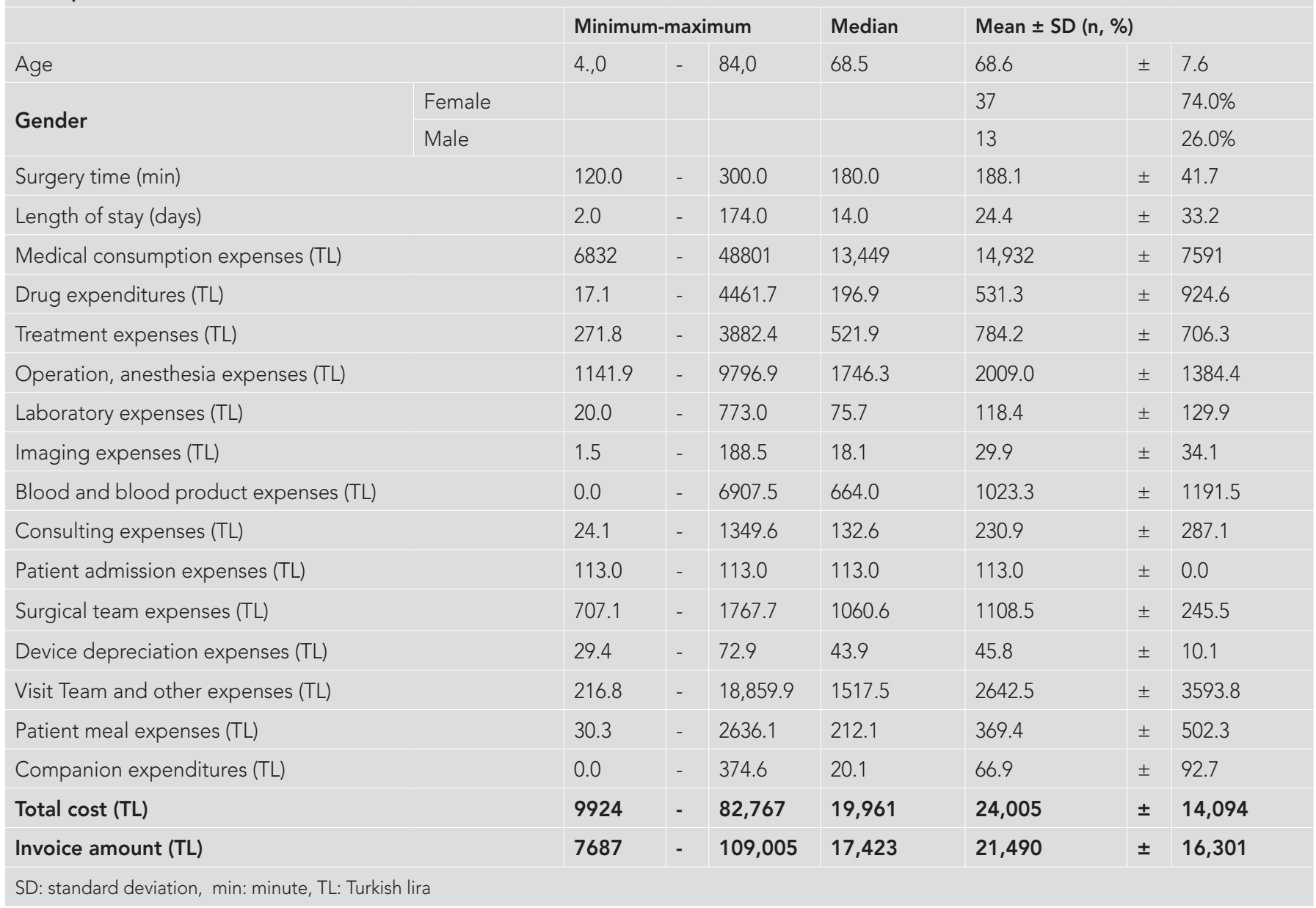


Table 2. Comparison of septic and aseptic revision knee arthroplasty data

\section{Comparison of septic and aseptic revision knee arthroplasty data}

\begin{tabular}{|c|c|c|c|c|c|c|c|c|c|c|c|}
\hline \multirow[b]{3}{*}{ Age } & & \multicolumn{3}{|l|}{ Aseptic } & & \multicolumn{4}{|l|}{ Septic } & \multirow{2}{*}{\multicolumn{2}{|c|}{$p$}} \\
\hline & \multicolumn{3}{|c|}{ Mean $\pm S D(n, \%)$} & \multirow{2}{*}{$\begin{array}{l}\text { Median } \\
7.6\end{array}$} & \multicolumn{3}{|c|}{ Mean \pm SD (n, \%) } & \multirow{2}{*}{$\begin{array}{l}\text { Median } \\
7.6\end{array}$} & \multirow[b]{2}{*}{71.0} & & \\
\hline & & 67.9 & \pm & & 68.0 & 70.0 & \pm & & & 0.485 & $\mathrm{~m}$ \\
\hline \multirow{2}{*}{ Sex } & Female & 25 & & $75.8 \%$ & & 12 & & $70.6 \%$ & & \multirow{2}{*}{0.693} & \multirow{2}{*}{$\chi^{2}$} \\
\hline & Male & 8 & & $24.2 \%$ & & 5 & & $29.4 \%$ & & & \\
\hline Surgery time (min) & & 188.5 & \pm & 39.3 & 180.0 & 187.4 & \pm & 47.1 & 180.0 & 0.967 & $\mathrm{~m}$ \\
\hline Length of stay (days) & & 16.5 & \pm & 27.2 & 7.0 & 39.7 & \pm & 38.8 & 29.0 & 0.000 & $\mathrm{~m}$ \\
\hline Medical consumption expenses (TL) & & 14690 & \pm & 8659 & 12564 & 15402 & \pm & 5114 & 14465 & 0.108 & $\mathrm{~m}$ \\
\hline Drug expenditures (TL) & & 231.6 & \pm & 562.5 & 106.9 & 1113.3 & \pm & 1200.0 & 658.2 & 0.000 & $\mathrm{~m}$ \\
\hline Treatment expenses (TL) & & 554.1 & \pm & 416.0 & 392.2 & 1230.7 & \pm & 927.7 & 815.4 & 0.000 & $\mathrm{~m}$ \\
\hline Operation. Anesthesia expenses (TL) & & 1696.1 & \pm & 769.2 & 1479.3 & 2616.5 & \pm & 2022.9 & 2191.4 & 0.006 & $\mathrm{~m}$ \\
\hline Laboratory expenses (TL) & & 81.9 & \pm & 88.3 & 61.1 & 189.3 & \pm & 167.4 & 153.0 & 0.000 & $\mathrm{~m}$ \\
\hline Imaging expenses (TL) & & 25.3 & \pm & 36.5 & 12.7 & 38.8 & \pm & 27.5 & 26.5 & 0.002 & $\mathrm{~m}$ \\
\hline Blood and blood product expenses (TL) & & 675.7 & \pm & 707.4 & 538.0 & 1697.9 & \pm & 1616.7 & 1044.4 & 0.000 & $\mathrm{~m}$ \\
\hline Consulting expenses (TL) & & 135.8 & \pm & 199.4 & 96.4 & 415.4 & \pm & 343.5 & 337.4 & 0.000 & $\mathrm{~m}$ \\
\hline Patient Admission expenses (TL) & & 113.0 & \pm & 0.0 & 113.0 & 113.0 & \pm & 0.0 & 113.0 & 1.000 & $\mathrm{~m}$ \\
\hline Surgical team expenses (TL) & & 1110.8 & \pm & 231.8 & 1060.6 & 1103.9 & \pm & 277.6 & 1060.6 & 0.967 & $\mathrm{~m}$ \\
\hline Device depreciation expenses ( $T L)$ & & 45.9 & \pm & 9.5 & 43.9 & 45.6 & \pm & 11.4 & 43.9 & 0.967 & $\mathrm{~m}$ \\
\hline Visit team and other expenses (TL) & & 1786.8 & \pm & 2951.4 & 758.7 & 4303.7 & \pm & 4205.9 & 3143.3 & 0.000 & $\mathrm{~m}$ \\
\hline Patient meal expenses (TL) & & 249.7 & \pm & 412.5 & 106.1 & 601.5 & \pm & 587.9 & 439.4 & 0.000 & $\mathrm{~m}$ \\
\hline Companion expenditures (TL) & & 51.5 & \pm & 80.6 & 13.4 & 96.8 & \pm & 109.1 & 93.7 & 0.130 & $\mathrm{~m}$ \\
\hline Total cost (TL) & & 21,448 & \pm & 13,438 & 18,083 & 28,968 & \pm & 14,406 & 26,236 & 0.001 & $\mathrm{~m}$ \\
\hline Invoice amount (TL) & & 19,282 & \pm & 11,905 & 15,307 & 25,775 & \pm & 22,378 & 19,168 & 0.038 & $\mathrm{~m}$ \\
\hline
\end{tabular}

billing costs in the septic group were significantly higher than the aseptic group $(p<0.05)$.

Factors causing infection include obesity, diabetes mellitus, male sex, American Society of Anesthesiologists score of $\geq 3$, diagnosis of osteonecrosis, diagnosis of posttraumatic arthritis, quadricepsrelease exposure, and operative time as a risk factor, with a $9 \%$ increased risk per 15 minimum increment. High-risk patients should be counseled, and modifiable clinical conditions should be optimized (15).

For long-term survival, total knee prosthesis is required to be aligned in neutral or with a slight anatomic valgus (16). Navigation should be applied to improve the results of TKA in line with the limb and component alignment (17).

Blood loss constitutes a significant cost item for the hospital. To reduce bleeding, techniques, such as skin heating, gentle soft tissue dissection during surgery, use of a new bipolar electrocautery device, use of cardiac stent, and if not contraindicated, discontinuation of anticoagulant drugs, and use of preoperative intra- and postoperative tranexamic acid drugs, can be applied $(18,19)$.
Studies conducted to shorten the length of hospital stay may be an appropriate attempt to reduce the cost of inpatient treatment. Patients undergoing revision TKA for non-septic reasons may be included in fast-track protocols. Outcome seems to be similar to those of primary TKA regarding length of stay, morbidity, and satisfaction (20).

\section{Study Limitations}

In the literature, the mean length of hospitalization of revision knee arthroplasty surgeries is reported to be shorter (21). We can explain the longer duration of hospitalization in our study with the lack of adequate home care services after discharge in our country; thus, pain control and rehabilitation process of the patients in the early postoperative period are performed in the hospitals. In addition, the reasons for the longer hospitalization period in patients undergoing septic revision knee surgery include inclusion of two-stage revision arthroplasty surgeries in the study, inclusion of the cost and duration of each step, and process of hospitalization for spacer and spacer revision to the data set of each patient, the use of some antibiotics parenterally administered in two-stage revision surgeries (aztreonam, vancomycin, imipenem, meropenem, linezolid, ertapenem, doripenem, sulbactam, 
5. Mut S, Ağırbaș İ. Hastanelerde Maliyet Analizi: Ankara'da Hizmet Sunan İkinci Basamak Bir Kamu Hastanesi'nde Uygulama. Mehmet Akif Ersoy Üniversitesi Sosyal Bilimler Enstitüsü Dergisi 2017; 9: 202-17.

6. Brimhall BB, Dean T, Hunt EL, Siegrist RB, Reiquam W. Age and laboratory costs for hospitalized medical patients. Arch Pathol Lab Med 2003; 127: 169-77.

7. Al- Fozan H, Dufort J, Kaplow M, Valenti D, Tulandi T. Cost analysis of myomectomy, hysterectomy, and uterine artery embolization. Am J Obstet Gynecol 2002; 187: 1401-4.

8. Gage H, Kenward G, Hodgetts TJ, Castle N, Ineson N, Shaikh L. Health system costs of in-hospital cardiac arrest. Resuscitation 2002; 54: 139-46.

9. Hansen K, Chapman G, Chitsike I, Kasilo O, Mwaluko G. The costs of HIV/ AIDS care at government hospitals in Zimbabwe. Health Policy Plan 2000; 15: 432-40

10. Yigit Ç, Peker S, Cankul I, Kostik Z, Alkan M, Özer M, et al. A Study on the Analysis of the Average Inpatient Cost at GATA Training Hospital. Gulhane Med J 2003; 45: 233-43. Sabancı Baltalimanı Training and Research Hospital Expertise Education Committee in Medicine Observational Research Ethics Committee (approval number: 16.10.2017-16).

Informed Consent: The demographic information were determined through hospital information management system records.

Peer-review: Externally peer-reviewed.

Author Contributions: Concept - F.D., S.U.D., Ö.C.; Design - F.D., S.U.D., T.Y.; Supervision - S.U.D., Ö.C., M.A.T.; Resources - F.D., S.U.D.; Materials - S.U.D.; Data Collection and/or Processing - F.D., S.U.D.; Analysis and/ or Interpretation - F.D., Ö.C., M.A.T.; Literature Search - F.D.; Writing Manuscript - F.D., Ö.C.; Critical Review - T.Y.

Conflict of Interest: The authors have no conflict of interest to declare.

Financial Disclosure: The authors declared that this study has received no financial support.

\section{REFERENCES}

1. Kurtz S, Ong K, Lau E, Mowat F, Halpern M. Projections of Primary and Revision Hip and Knee Arthroplasty in the United States from 2005 to 2030. J Bone Joint Surg Am 2007; 89: 780-5.

2. Crowe JF, Sculco TP, Kahn B. Revision Total Hip Arthroplasty. Clin Orthop Relat Res 2003; 413: 175-82.

3. 04.02.2018 Değişiklik Tebliği İșlenmiş Güncel 2013 SUT: Available from: http://www.sgk.gov.tr/wps/portal/sgk/tr/kurumsal/merkez-teskilati/ana_ hizmet_birimleri/gss_genel_mudurlugu/anasayfa_duyurular/degisiklik_ tebligi_islenmis_guncel_sut_08022018, Accessed April 19, 2018

4. Sağlık Bakanlığı Finansal Analiz Daire Başkanlığı, Maliyet Analizi Çalışmalarında Gider Belirleme Tabloları, Mart 2014 (Revize Ocak-2015): Available from: https://khgm.saglik.gov.tr/ Dosyalar/5796ea7a9ecf44aa832b697631f7bc56.pdf, Accessed April 19, 2018
11. Özkan O, Ağırbaş İ. Radyoloji Departmanında Birim Maliyet Analizi Ve Örnek Bir Uygulama. Mehmet Akif Üniversitesi Sosyal Bilimler Enstitüsü Dergisi 2015; 13: 115-28.

12. Hebert CK, Williams RE, Levy RS, Barrack RL. Cost of Treating an Infected Total Knee Replacement. Clin Orthop Relat Res 1996; 331: 140-5.

13. Oduwole KO, Molony DC, Walls RJ, Bashir SP, Mulhall KJ. Increasing financial burden of revision total knee arthroplasty. Knee Surg Sports Traumatol Arthrosc 2010; 18: 945-8.

14. Kasch R, Merk S, Assmann G, Lahm A, Napp M, Merk H, et al. Comparative Analysis of Direct Hospital Care Costs between Aseptic and Two-Stage Septic Knee Revision. PLoS One 2017; 12: e0169558.

15. Namba RS, Inacio MCS, Paxton EW. Risk Factors Associated with Deep Surgical Site Infections After Primary Total Knee Arthroplasty: an analysis of 56,216 knees. J Bone Joint Surg Am 2013; 95: 775-82.

16. Ritter MA, Faris PM, Keating EM, Meding JB. Postoperative Alignment of Total Knee Replacement Its Effect on Survival. Clin Orthop Relat Res 1994; 299: 153-6.

17. Anderson KC, Buehler KC, Markel DC. Computer Assisted Navigation in Total Knee Arthroplasty: comparison with conventional methods. J

18. Spahn DR. Anemia and Patient Blood Management in Hip and Knee Surgery: a systematic review of the literature. Anesthesiology 2010; 113: 482-95.

19. Tian P, Liu WB, Li ZJ, Xu GJ, Huang YT, Ma XL. The efficacy and safety of tranexamic acid in revision total knee arthroplasty: a meta-analysis. BMC Musculoskelet Disord 2017; 18: 273

20. Husted $\mathrm{H}$, Otte KS, Kristensen BB, Kehlet H. Fast-track revision knee arthroplasty. Acta Orthop 2011; 82: 438-40.

21. Liodakis E, Bergeron SG, Zukor DJ, Huk OL, Epure LM, Antoniou J. Perioperative Complications and Length of Stay After Revision Total Hip and Knee Arthroplasties: An Analysis of the NSQIP Database. J Arthroplasty 2015; 30: 1868-71. Arthroplasty 2005; 20: 132-8 